\title{
Assessment of regional left ventricular function by magnetic resonance
}

\author{
S R UNDERWOOD, R S O REES, P E SAVAGE, R H KLIPSTEIN, D N FIRMIN, \\ K M FOX, P A POOLE-WILSON, D B LONGMORE
}

From the National Heart and Chest Hospitals, London

SUMMARY The ability of magnetic resonance to determine regional left ventricular function was investigated in 18 patients - 13 with coronary artery disease (nine with previous infarction), one with congestive cardiomyopathy, one with mitral stenosis, one with an atrial septal defect, and two without detectable cardiac abnormality. Coronal magnetic resonance images were acquired through the aortic valve and sagittal images were acquired in the plane of widest diameter of the left ventricle seen in the coronal image, both at end diastole and end systole. Regional wall motion assessed by magnetic resonance was compared with the results of anteroposterior and left lateral $x$ ray ventriculograms by two independent observers. The left ventricular wall was divided into three segments in each plane and the motion of the segments was classified as normal, hypokinetic, akinetic, or dyskinetic. Muscle thickness was measured in each segment of the magnetic resonance images and was considered to be abnormal if in the systolic images it was $<75 \%$ of that in neighbouring segments or if it failed to increase by at least $25 \%$ between diastole and systole. Wall motion assessments by the two methods agreed in 68 of 105 segments analysed, but differed by one class in 32 segments and by two classes in five segments. The differences can be explained by the conditions under which the investigations were performed and by the disparity between a tomographic section and an $x$ ray projection. Magnetic resonance showed 25 segments to have abnormal wall thickness. Only one patient with infarction did not have an area of wall thinning and no patient without infarction had an area of thinning.

It is concluded that magnetic resonance allows an accurate non-invasive assessment of left ventricular wall motion and thickness.

Magnetic resonance allows high resolution tomographic imaging of most organs in the body. Images of static organs, such as the brain and spinal cord, are excellent and these are becoming increasingly valuable in clinical practice. It is possible to produce images of the heart at any point of the cardiac cycle by means of electrocardiographic gating, and image acquisition can be arranged so that flowing blood gives no magnetic resonance signal. This provides high contrast between blood and myocardium without the use of contrast agents and allows the demon-

Requests for reprints to Dr S R Underwood, Magnetic Resonance Unit, The National Heart and Chest Hospitals, 30 Britten Street, London SW36NN.

Accepted for publication 11 June 1986 stration of cardiac anatomy ${ }^{1-3}$ and both global $^{4-6}$ and regional ventricular function. ${ }^{7}$ Although other non-invasive techniques such as echocardiography and radionuclide ventriculography can also provide this information, magnetic resonance is particularly versatile because of its high resolution and its ability to image in any plane. In addition, because it can be used to measure blood flow ${ }^{8-10}$ and to study biochemical effects through the relaxation variables $T_{1}$ and $T_{2}{ }^{11-13}$ and through magnetic resonance spectroscopy, ${ }^{14}$ it is likely to be valuable in the investigation of cardiovascular disease.

We have used magnetic resonance to assess regional left ventricular wall motion and have compared these findings with those of $x$ ray ventriculography. We also investigated the relation between wall motion and thickness, another indicator of regional function. 

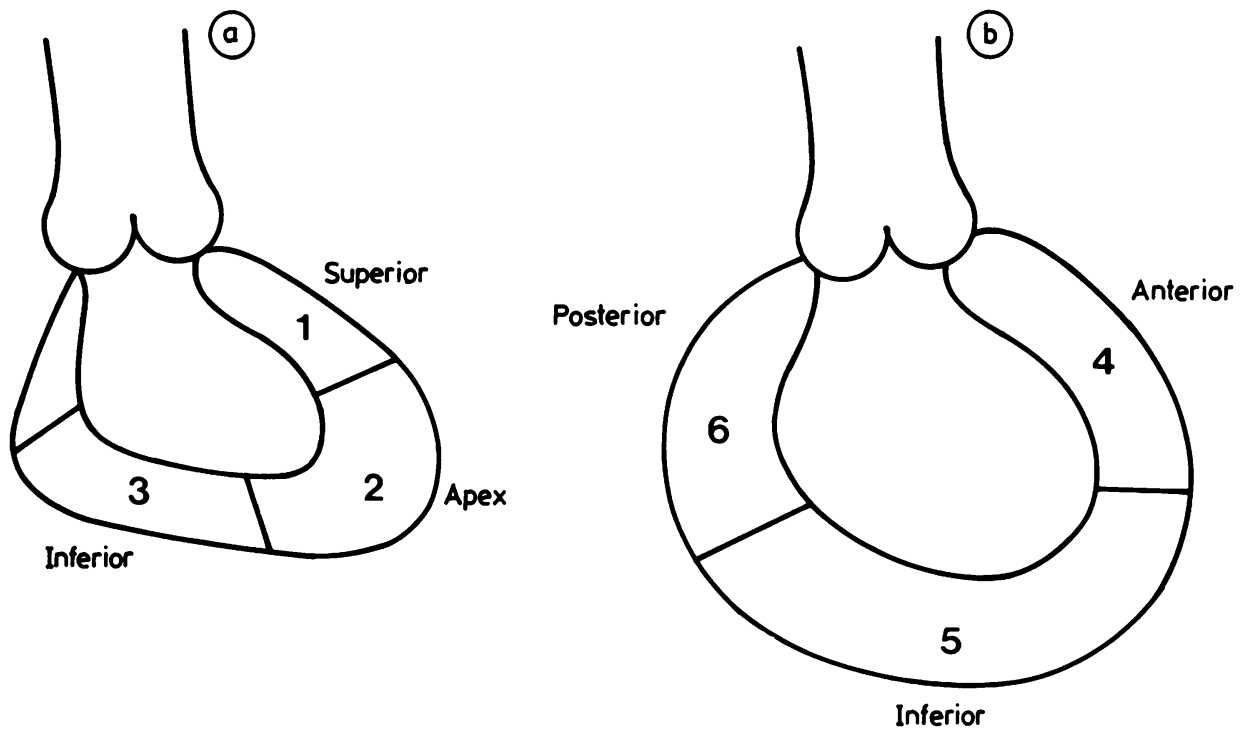

Fig 1 Segmentation of the coronal (a) and sagittal (b) magnetic resonance images and the anteroposterior (a) and lateral (b) ventriculograms for the analysis of wall motion and thickness.

\section{Patients and methods}

\section{PATIENTS}

We studied 18 patients (17 men and one woman, mean age 52 , range 28 to 72 ). Nine had had a myocardial infarction (diagnosis by history and electrocardiography); four had coronary artery disease without infarction; one had congestive cardiomyopathy (possibly alcoholic); one had rheumatic mitral stenosis; one an atrial septal defect; and two had chest pain, but investigations (including coronary arteriography) had not shown cardiac abnormality.

\section{MAGNETIC RESONANCE}

Magnetic resonance images were acquired with a Picker International superconducting machine operating at $0.24 \mathrm{~T}$. The images were reconstructed by two dimensional Fourier transformation of two averages of 128 spin echo sequences with an echo time of $40 \mathrm{~ms}$, so that the acquisition time of each image was between 3 and 4 minutes depending upon heart rate. Coronal images were acquired through the centre of the aortic valve, and sagittal and transverse images were acquired in the planes of widest vertical and lateral diameters of the left ventricular cavity respectively. In each plane an end diastolic image was acquired immediately after the $R$ wave of the electrocardiogram and an end systolic image was timed to coincide with the second heart sound. Tracings of the left ventricular endocardium at diastole and systole were superimposed and divided into three segments in each plane (fig 1). Wall motion in each segment was classified as normal, hypokinetic, akinetic, or dyskinetic by two independent observers (SRU and RHK) without knowledge of the ventriculographic findings. Wall thickness was also measured to the nearest $0.25 \mathrm{~mm}$ by means of dividers and a vernier scale. Abnormality was defined by two different criteria: firstly, if a systolic segment was $<75 \%$ of the mean of the thickness of neighbouring segments, and secondly if thickness failed to increase between diastole and systole by $>25 \%$ of the diastolic measurement.

\section{$X$ RAY VENTRICULOGRAPHY}

The coronal images were compared with the end diastolic and end systolic frames of an anteroposterior $x$ ray left ventriculogram, and the sagittal images were compared with a lateral ventriculogram. Transverse images were not used in the ven-

Table 1 Number of segments in each magnetic resonance wall motion class and the numbers in which there was disagreement with ventriculography by one and two classes

\begin{tabular}{lcll}
\hline & $\begin{array}{l}\text { Total } \\
\text { segments }\end{array}$ & $\begin{array}{l}\text { Disagree by } \\
\text { 1 class }\end{array}$ & $\begin{array}{l}\text { Disagree by } \\
\text { 2 classes }\end{array}$ \\
\hline Normal & 63 & 16 & 1 \\
Hypokinetic & 21 & 10 & 0 \\
Akinetic & 17 & 6 & 3 \\
Dyskinetic & 4 & 0 & 1 \\
Total & 105 & $32\left(30^{\circ}\right)$ & $5\left(5^{\circ}\right)$ \\
\hline
\end{tabular}


Table 2 Number of segments according to magnetic resonance wall motion class in the patients with and without previous infarction

\begin{tabular}{lcc}
\hline & $\begin{array}{l}\text { No infarction } \\
(9 \text { patients) }\end{array}$ & $\begin{array}{l}\text { Infarction } \\
(9 \text { patients) }\end{array}$ \\
\hline Normal & 46 & 17 \\
Hypokinetic & 6 & 17 \\
Akinetic & 1 & 16 \\
Dyskinetic & 1 & 4 \\
Total & 54 & 54 \\
\hline
\end{tabular}

$\chi^{2}=33.64, \mathrm{p}<0.001$.

triculographic comparison. A cycle was chosen early after injection but remote from extrasystoles, and wall motion was analysed from the angiograms in a similar manner to the magnetic resonance images (observers RSOR and SRU).

\section{Results}

WALL MOTION

The wall motion of 105 segments was analysed; one
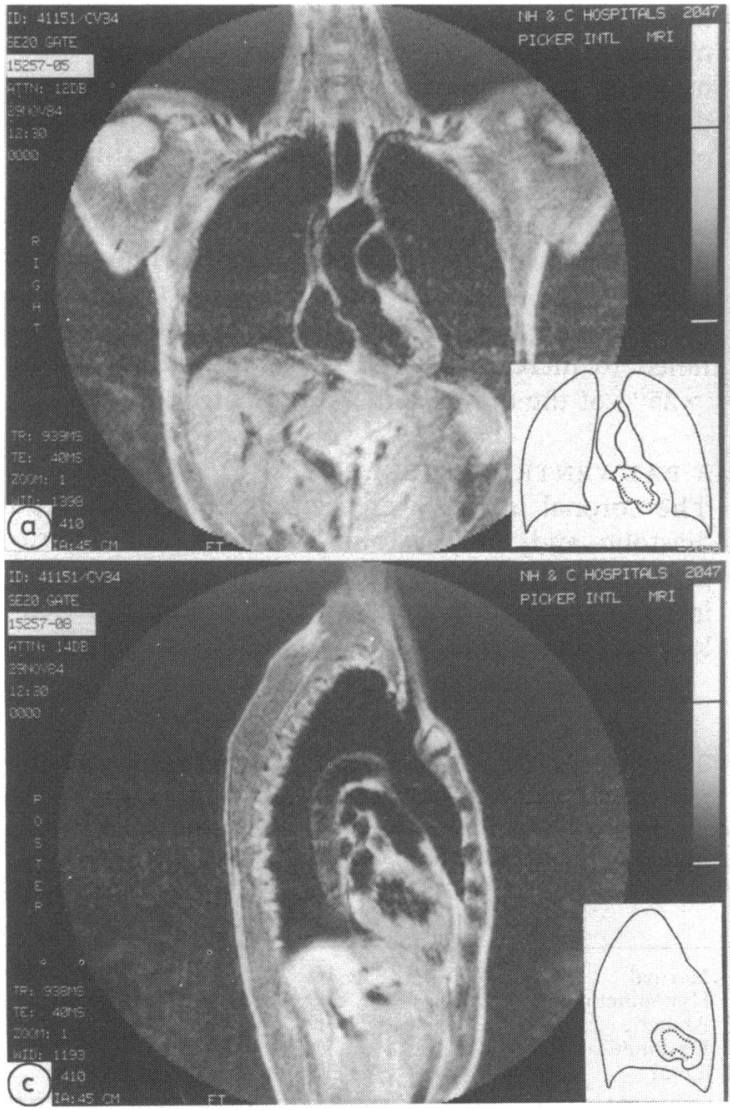

lateral ventriculogram was uninterpretable. The observers assigned the same wall motion class in 93 segments of the magnetic resonance images, but differed by one class in 11 segments, and by two classes in one segment. For the ventriculograms they agreed in 88 segments and disagreed by one class in 15 segments, and by two classes in two segments. These discrepancies arose principally because of different segmentation of the left ventricular contours and were settled by collaboration.

Table 1 shows the number of segments in each magnetic resonance wall motion class, and the numbers in which there was disagreement by one and two classes when compared with ventriculography. In no segment was there disagreement by three classes. Of the five segments with disagreement by two classes, three were in patients with previous infarction; in these patients magnetic resonance showed akinesis and wall thinning but ventriculography showed normal motion. The fourth was in a patient with coronary artery disease without infarction in whom magnetic resonance showed normal wall motion and thickness but ventriculography

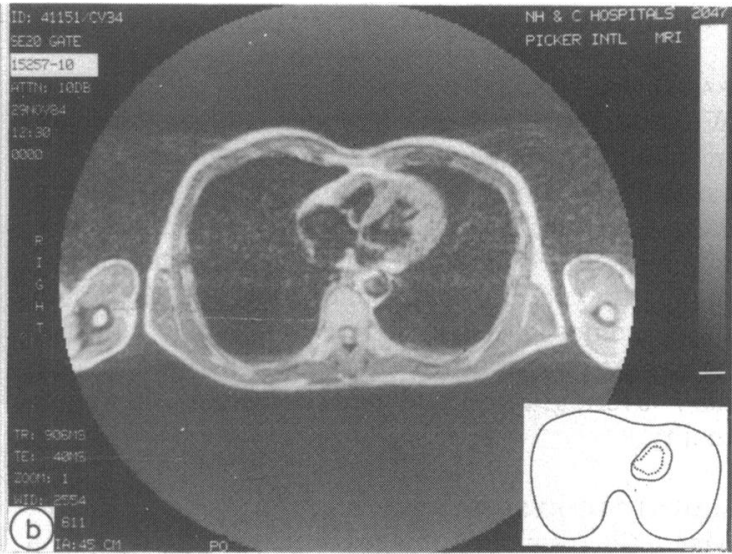

Fig 2 Magnetic resonance images showing normal findings. (a) Coronal, (b) transverse, and (c) sagittal images at end systole of a 42 year old smoker being investigated for atypical chest pain. Cardiac catheterisation showed normal left ventricular contraction and coronary arteries. The end diastolic left ventricular endocardial contours are also shown with the end systolic contours superimposed as dotted lines. Myocardial thickness and contraction are symmetrical. 
Table 3 Wall motion classes in the segments with abnormal wall thickness as defined by the two criteria $a$ and $b$

\begin{tabular}{lrccl}
\hline & (a) Thin & $\begin{array}{l}\text { (b) Failure } \\
\text { to increase }\end{array}$ & (a) Alone & (b) Alone \\
\hline Normal & 3 & 5 & 0 & 2 \\
Hypokinetic & 5 & 7 & 1 & 3 \\
Akinetic & 11 & 11 & 1 & 1 \\
Dyskinetic & 2 & 2 & 0 & 0 \\
Total & 21 & 25 & 2 & 6 \\
\hline
\end{tabular}

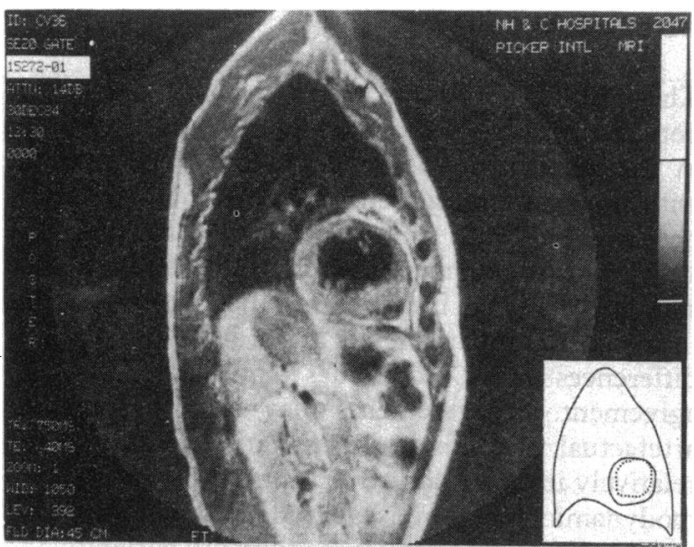

Fig 3 Magnetic resonance image showing anterior infarction. End systolic sagittal image of a 57 year old man with a six year history of angina with anterior infarction four years previously. Cardiac catheterisation showed anterior and apical akinesis with three vessel disease and an occluded left anterior descending artery. There is anterior thinning and akinesis and the transverse images showed that this extended to the septum.

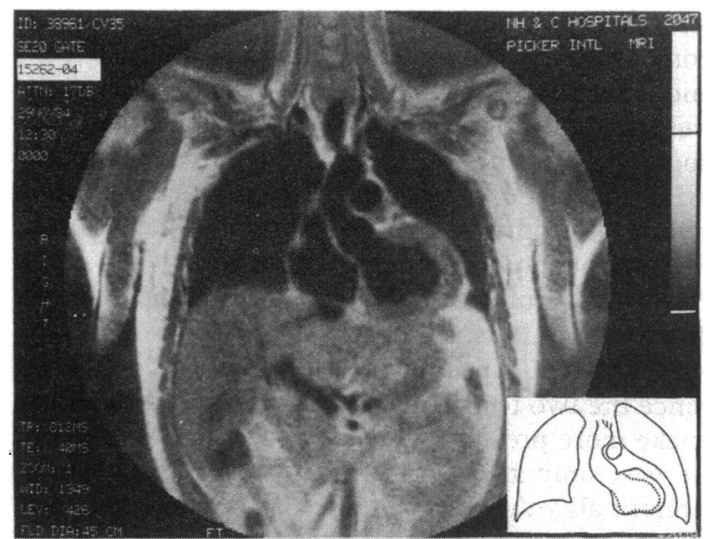

Fig 4 Magnetic resonance image showing inferior infarction. A 45 year old man with inferior infarction two years previously and continuing angina of effort. Cardiac catheterisation showed inferior akinesis and severe three vessel disease with a $90 \%$ stenosis of a dominant right coronary artery. The end systolic coronal magnetic resonance image shows inferior wall thinning and akinesis.

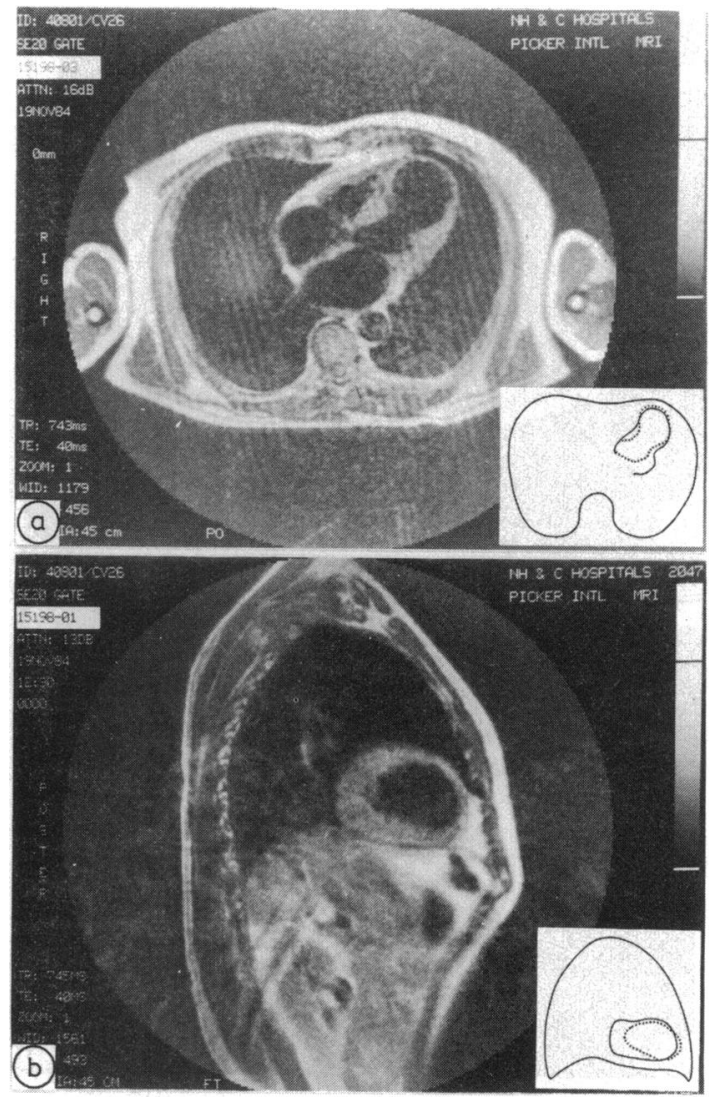

Fig 5 Magnetic resonance image showing left ventricular aneurysm. (a) Transverse and (b) sagittal end systolic images of a 51 year old man with previous anterior infarction. Cardiac catheterisation showed single vessel disease with an occluded left anterior descending artery and an antero-apical aneurysm.

showed akinesia. The fifth was in the patient with atrial septal defect. Magnetic resonance showed paradoxical septal motion. This was also seen by echocardiography; however, ventriculography showed hypokinesis.

Table 2 shows the distribution of magnetic resonance wall motion classes in the patients with and those without previous infarction. All patients with previous infarction had at least one akinetic or dyskinetic segment, whereas only two patients without infarction had these abnormalities. One was the patient with atrial septal defect and paradoxical septal motion and the other was the patient with congestive cardiomyopathy. The presence of akinesis or dyskinesis was therefore a sensitive although not specific indicator of previous infarction. 


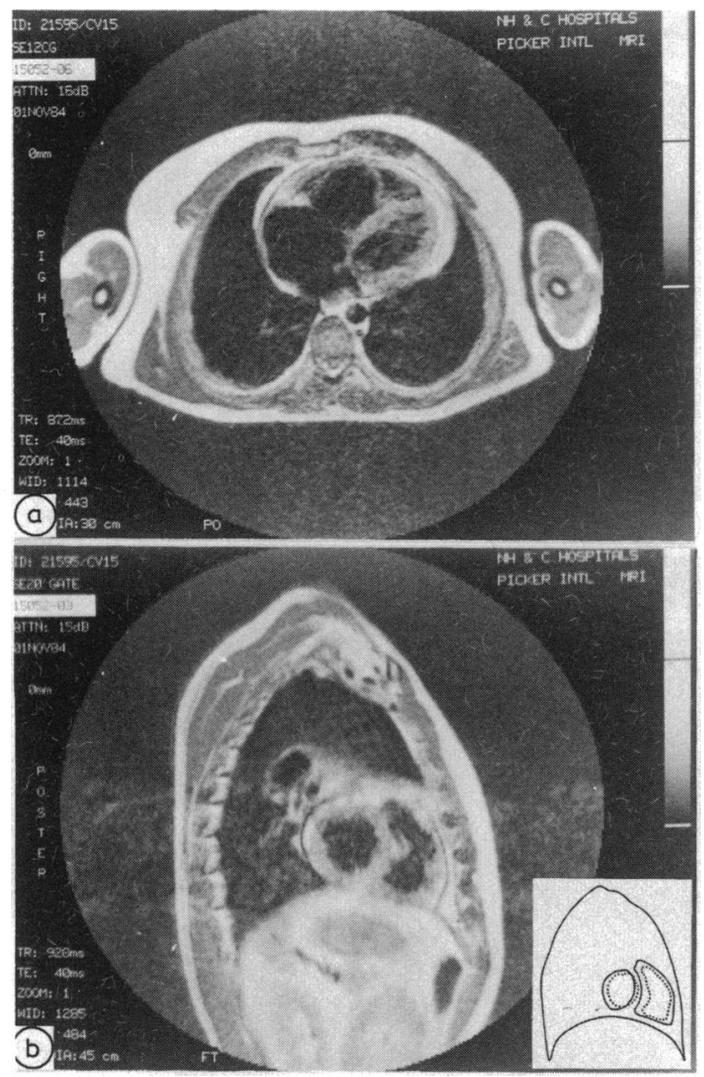

Fig 6 Magnetic resonance image showing atrial septal defect. (a) Diastolic transverse and (b) systolic sagittal images of a 28 year old man with an atrial septal defect. An ostrium secundum defect is seen in the transverse image and the right heart is dilated. The sagittal contours show paradoxical septal motion caused by the hyperkinetic right ventricle. Stroke volume measurements from the magnetic resonance images showed the pulmonary to systemic flow ratio to be $2 \cdot 3$ to 1.25

\section{WALL THICKNESS}

Twenty one segments were abnormal by the first criterion ( $<75 \%$ of the mean of the thickness of adjacent segments at end systole), and in only two of these was there a normal increase in thickness between diastole and systole. Twenty five segments were abnormal by the second criterion (failure to increase in thickness by more than $25 \%$ between diastole and systole), and six of these were of normal systolic thickness. Thus although both criteria of abnormal wall thickness usually occurred together, either could occur alone. Both abnormalities were seen only in patients with previous infarction, but one patient who had had an inferior infarction three months previously did not have any abnormality of wall thickness. No patient without previous infarction had abnormal wall thickness by either criterion.

Table 3 shows the wall motion classes in the segments with abnormal thickness. Although most abnormal segments were either dyskinetic or akinetic, a considerable number were hypokinetic or had normal motion.

Figures 2 to 6 show examples of magnetic resonance images from patients with various conditions.

\section{Discussion}

The results show that there is good agreement between magnetic resonance and ventriculography in the assessment of left ventricular wall motion, with important disagreement (more than one class) occurring in only $5 \%$ of segments. The technique of $x$ ray contrast ventriculography is often used as a standard by which newer techniques are judged, but in any such comparison it is important to be aware of differences in the techniques that will lead to disagreement. Disagreements may be either real or artefactual. Real disagreements arise because of the relatively invasive nature of ventriculography. Haemodynamic function is altered and the effects of rapid injection of contrast medium are variable. ${ }^{1516}$ It is possible for instance that the rapid injection of contrast in the patient with atrial septal defect created a temporary left sided volume overload, so that the septum moved as part of the left ventricle rather than paradoxically, as was seen by magnetic resonance in the resting state with right ventricular overload. Artefactual disagreements arise because $x$ ray ventriculography produces a planar projection of the ventricle whereas magnetic resonance produces a tomographic section. This means that the two techniques may not demonstrate the same part of the ventricular wall, because the plane of the ventriculographic outline may be oblique when compared with the plane of the magnetic resonance section (fig 7). In addition, the degree of obliqueness may vary throughout the cardiac cycle.

Another potential source of disagreement arises from the semiquantitative way in which wall motion was assessed. This type of assessment was deliberate since the two techniques are sufficiently different to make more precise quantitative agreement unlikely. It was only the ability to detect and categorise abnormality that was being tested. The classification of wall motion as normal, hypokinetic, akinetic, and dyskinetic is in widespread clinical use, and whereas observers often differ by one category they are unlikely to differ by more. The extent of agreement between the two observers for either ventriculography or magnetic resonance is a measure of the validity of the method being examined. 


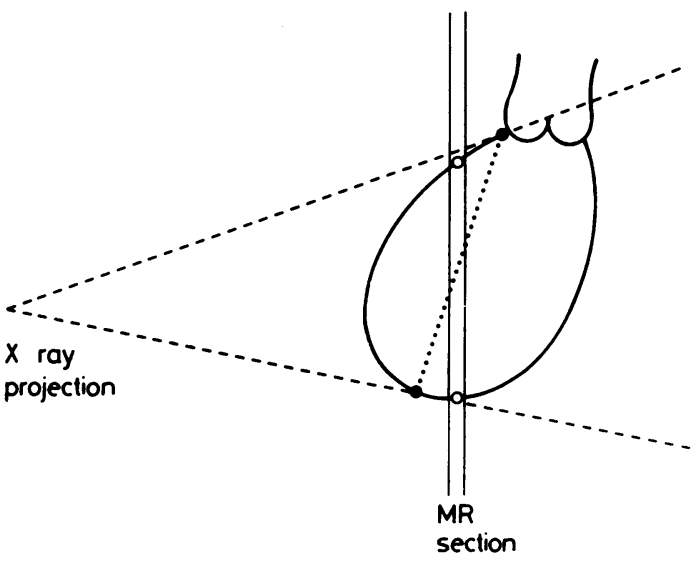

Fig 7 The ventricular wall forming the borders of the $x$ ray ventriculogram may not correspond to that of the tomographic magnetic resonance image.

Magnetic resonance measurements of wall thickness have been shown to be accurate ${ }^{4}$ and previously established normal values were used to define the criteria of normality in this study. ${ }^{67}$ Our results show that wall thickness as well as motion is sensitive in the detection of previous infarction but both abnormalities do not always occur together. Since wall motion may also be caused by factors other than myocardial contraction, this is not surprising. Both criteria of abnormal wall thickness usually occurred together, but the thickness of six segments failed to increase between diastole and systole despite their not being thinner than neighbouring segments at systole; this may have been because the neighbouring segments were not necessarily normal. We did not examine how soon wall thinning occurred after infarction but the patient with the most recent infarct (three months) had normal wall thickness. It is likely that failure to thicken during systole will be an early finding and diastolic thinning a later one. Although the wall thickness measurements were sensitive for previous infarction, they are not likely to be specific because patients with non-coronary myocardial disease may also have wall thinning.

We did not attempt to compare the location of abnormalities with the electrocardiographic site of infarction because in the planes that we used the ventricular borders did not correspond to an easily defined wall. Oblique images parallel to the long axis of the left ventricle can now be acquired and are the preferred planes for ventricular volume studies and for wall motion and thickness. ${ }^{17-19}$ At the time of this study, our machine, in common with many others, was not able to acquire oblique images. The use of coronal and sagittal planes may explain some of the unexpected findings because the ventricular wall will not necessarily pass perpendicularly through the image plane.

A full description of regional function cannot be obtained from single tomographic sections and it is difficult to interpret the large numbers of images from multiple sections. There are already techniques to reduce several tomographic images to a single image displaying three dimensional data and a single parametric image showing motion of all parts of the ventricle may be created from a series of short axis sections of the ventricle. ${ }^{20}$ Magnetic resonance may be used in the future to produce parametric images that show not only wall motion and thickness but also other variables such as rates and timing of contraction. Timing is an important feature of regional ventricular function and abnormal areas may contract later than normal. ${ }^{21}$ This will introduce inaccuracies into measurements made from a single systolic image but cine imaging will avoid this. ${ }^{22-24}$

\section{Conclusion}

Accurate non-invasive assessment of regional left ventricular function is possible with magnetic resonance. The ability to demonstrate cardiac anatomy and global function and the potential for the measurement of blood flow and the provision of biochemical information suggest that it will become an important technique in the investigation of patients with cardiovascular disease.

We thank the following for financial support: the Board of Governors of the National Heart and Chest Hospitals, the Coronary Artery Disease Research Association (CORDA), the League of Friends of the Brompton Hospital, the Viscount Royston Trust, the Halley Stewart Trust, the Charles Wolfson Charitable Foundation, and GEC/Picker International. We are also grateful for the assistance of Sister Elizabeth Burman and Mr Karl Lotey.

\section{References}

1 Steiner RE, Bydder GM, Selwyn A, et al. Nuclear magnetic resonance imaging of the heart: current status and future prospects. Br Heart $\mathcal{F}$ 1983;50:202-8.

2 Higgins CB, Byrd BF, McNamara MT, et al. Magnetic resonance imaging of the heart: a review of the experience in 172 subjects. Radiology 1985;155: 671-9.

3 Higgins CB, Kaufman L, Crooks LE. Magnetic resonance of the cardiovascular system. Am Heart $\mathcal{f}$ 1985;109:136-52. 
4 Longmore DB, Klipstein RH, Underwood SR, et al. The dimensional accuracy of magnetic resonance in studies of the heart. Lancet 1985;i:1360-2.

5 Byrd BF III, Schiller NB, Botvinick EH, Higgins CB. Normal cardiac dimensions by magnetic resonance imaging. Am f Cardiol 1985;55:1440-2.

6 Friedman BJ, Waters J, Kwan OL, DeMaria AN. Comparison of magnetic resonance imaging and echocardiography in determination of cardiac dimensions in normal subjects. $\mathcal{F} \mathrm{Am}$ Coll Cardiol 1985;5:1369-76.

7 Fisher MR, von Schulthess GK, Higgins CB. Multiphasic cardiac magnetic resonance imaging: normal

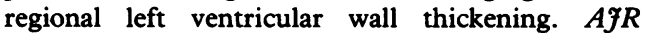
1985;145:27-30.

8 Axel L. Blood flow effects in MRI. $A f R$ 1984; 143:1167-74.

9 Bryant DJ, Payne JA, Firmin DN, Longmore DB. Measurement of flow with NMR imaging using a gradient pulse and phase difference technique. f Comput Assist Tomogr 1984;8:588-93.

10 Nayler GL, Firmin DN, Longmore DB, Randell CP. Cine MR blood flow imaging [Abstract]. Radiology 1985;157(P):313.

11 McNamara MT, Higgins CB, Schechtmann N, et al. Detection and characterisation of acute myocardial infarction in man with use of gated magnetic resonance. Circulation 1985;71:717-24.

12 Higgins CB, Lanzer $P$, Stark $O$, et al. Imaging by nuclear magnetic resonance in patients with chronic ischaemic heart disease. Circulation 1984;69:523-31.

13 Thompson RC, Johnston D, Dinsmore RO, et al. Serial magnetic resonance imaging in patients following recent myocardial infarction: serial appearance and characterisation of the healing myocardium [Abstract]. Proceedings of the fourth annual meeting of the Society of Magnetic Resonance in Medicine, London 1985. Berkeley: Society of Magnetic Resonance in Medicine, 1985:678-9.

14 Gadian DG. Nuclear magnetic resonance and its applications to living systems. Oxford: Clarendon Press, 1982.

15 Higgins CB. Effects of contrast materials on left ventricular function. Invest Radiol 1980;15(suppl):
220-31.

16 Sheehan FH, Stewart DK, Dodge HT, Mitten S, Bolson EL, Brown BG. Variability in the measurement of regional left ventricular wall motion from contrast angiograms. Circulation 1983;68:550-9.

17 Akins EW, Hill JA, Fitzsimmons JR, Pepine CJ Williams $\mathrm{CM}$. Importance of imaging plane for magnetic resonance imaging of the normal left ventricle. Am F Cardiol 1985;56:366-72.

18 Underwood SR, Walton S, Laming PJ, et al. Left ventricular volume and ejection fraction determined by gated blood pool emission tomography. Br Heart $\mathcal{f}$ 1985;53:216-22.

19 Feiglin DH, George CR, MacIntyre WJ, et al. Gated cardiac magnetic resonance structural imaging: optimization by electronic axial rotation. Radiology 1985;154:129-32.

20 Underwood SR, Walton S, Laming PJ, et al. Three dimensional quantification of left ventricular wall motion by ECG gated blood pool emission tomography [Abstract]. Br Heart $\mathcal{f}$ 1985;53:90.

21 Walton S, Yiannikas J, Jarritt PH, Brown NJG, Swanton RH, Ell PJ. Phasic abnormalities of left ventricular emptying in coronary artery disease. $\mathrm{Br}$ Heart $\mathcal{f}$ $1981 ; 46: 245-53$.

22 Ordidge RJ, Mansfield P, Doyle M, et al. "Real time" moving images by NMR. In: Witcofski RL, Karstaedt N, Partain CL, eds. Proceedings of the international symposium in NMR imaging. Winston Salem, NC: Bowman Gray School of Medicine Press, 1982:89-92.

23 Waterton JC, Jenkins JPR, Zhu XP, Love HG, Isherwood I, Rowlands DJ. Magnetic resonance (MR) cine imaging of the human heart. $\mathrm{Br} \mathcal{F}$ Radiol 1985;58:711-6.

24 Feiglin DH, Moodie DS, O'Donnell JK, Go RT, Sterba R, MacIntyre WJ. Evaluation of congenital heart disease by cine magnetic resonance imaging [Abstract]. Eur F Nucl Med 1985;11:A18.

25 Underwood SR, Klipstein RH, Firmin DN, et al. Magnetic resonance quantification of atrial shunting and valvar regurgitation [Abstract]. Br Heart $\mathcal{F}$ 1985;54: 616. 